\title{
A Case of Small Bowel Obstruction Due to a Paracecal Hernia
}

\author{
Eun-Jung Jang, Seung Hyun Cho' ${ }^{1}$, Dae-Dong Kim \\ Colorectal Clinic, Department of Surgery, Daegu Catholic University Medical Center, Daegu; ${ }^{1}$ Department of Radiology, Daegu Fatima \\ Hospital, Daegu, Korea
}

Internal hernias are rare causes of small bowel obstruction, and one such internal hernia is the paracecal hernia. We report a case of a small bowel obstruction related to a paracecal hernia in which a preoperative diagnosis was made on computed tomography. A laparotomy was performed for definitive diagnosis and treatment. The surgery achieved a good outcome.

Keywords: Small bowel obstruction; Internal hernia; Paracecal hernia

\section{INTRODUCTION}

An internal hernia (IH) is an infrequent cause of small bowel obstruction (SBO), with a reported autopsy incidence of 0.2 to $0.9 \%$, and is the cause of small-bowel obstruction in 0.6 to $5.8 \%$ of the cases $[1,2]$. Preoperative diagnosis of internal hernia is extremely difficult because of the nonspecific clinical presentation. Abdominal computed tomography (CT) plays an important role in the evaluation and management of patients with SBO. Urgent surgical intervention to prevent strangulation is essential. We are reporting a case of a SBO related to a paracecal hernia.

\section{CASE REPORT}

An 84 year-old woman visited the emergency room presenting with 2 days of abdominal distension and vomiting. There was no prior medical or surgical history of note. Recently, she had

Received: September 16, 2010 Accepted: November 8, 2010

Correspondence to: Dae-Dong Kim, M.D.

Colorectal Clinic, Department of Surgery, Daegu Catholic University Medical

Center, 3056-6 Daemyeong 4-dong, Nam-gu, Daegu 705-718, Korea

Tel: +82-53-650-4065, Fax: +82-53-624-7185

E-mail: silverpop@daum.net

(C) 2011 The Korean Society of Coloproctology

This is an open-access article distributed under the terms of the Creative Commons Attribution NonCommercial License (http://creativecommons.org/licenses/by-nc/3.0) which permits unrestricted non-

commercial use, distribution, and reproduction in any medium, provided the original work is properly cited. been admitted to the orthopedic hospital with the chief complaint of back pain. Clinical examination revealed abdominal distension, but no visible or palpable abdominal mass or wall hernias. There was tenderness over the entire abdomen, but no peritoneal sign. Leukocytosis $\left(12.9 \times 10^{3} / \mu \mathrm{L}\right)$ with a predominance of neutrophils (86.8\%) was noted on routine hematology. Plain abdominal X-ray showed dilated small bowel loops on mid-abdomen. Intravenous contrast-enhanced abdominal CT scan showed dilatation of small bowel loops and herniation of a short segment of the small bowel through the right cecal fossa (Figs. 1, 2). The patient was taken immediately for an exploratory laparotomy, which revealed a segment of the distal jejunum entrapped in the cecal fossa. The entrapped jejunum was released, and lysis was done between two peritoneal folds (Figs. $3,4)$. The postoperative course was uneventful.

\section{DISCUSSION}

Internal hernias may infrequently cause $\mathrm{SBO}$, which may be fatal because of the risk of strangulation of the hernial content. Paracecal hernias account for a minority of $\mathrm{IH}$-related SBOs [3, 4]. These hernias are the result of alterations in the normal process of intestinal rotation during embryonic development. The embryological development of the cecum includes budding, exteriorization into the umbilicus and subsequent retraction onto the posterior abdominal wall, which usually predisposes the paracecal fossa [5] to the formation of a number of pockets or recesses. 
Journal of The Korean Society of A Case of Small Bowel Obstruction Due to a Paracecal Hernia

Coloproctology Eun-Jung Jang, et al.

An excellent classification for boundaries of hernias was formulated by Meyer [6, 7], who described six: paracecal sulci, cecal fossa, cecal recess, superior ileocecal recess, inferior ileocecal recess, and retrocecal recess. Paracecal sulci are lateral depressions of the peritoneum invested on the cecum, but recesses may be absent. The cecal fossa is a groove that is formed by two peritoneal folds. The lateral fold is a continuation of the white line of Toldt and the medial fold originating from the ileocecal angle, medial aspect of the cecum. The cecal recess is formed by folds described for the cecal fossa, but in this instance, the cecum is entirely retroperitoneal. Superior and inferior ileocecal recesses are formed by a peritoneal fold originating from the terminal ileum to the cecum. A retrocecal recess is formed by the cecum anteriorly, the iliac fossa posteriorly, the right colic

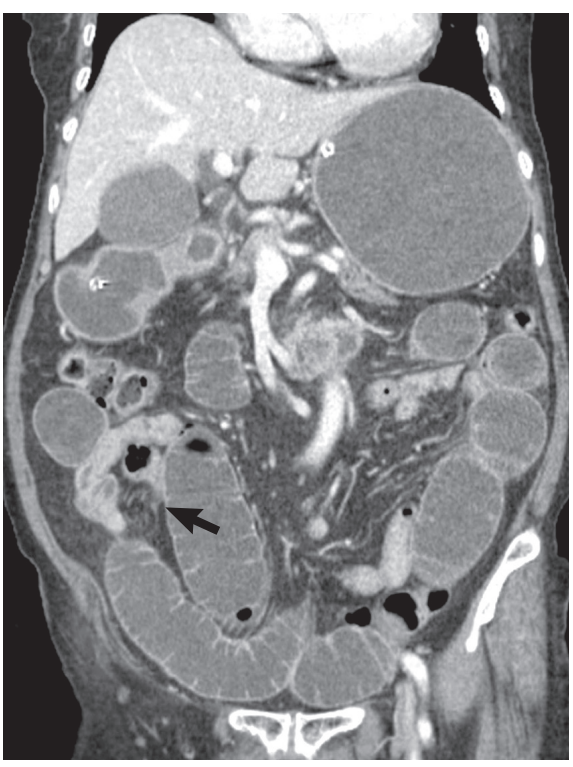

Fig. 1. Paracecal hernia through the right cecal fossa in an 84-year-old woman. Contrast-enhanced computed tomography scan shows dilated small bowel loops and herniation of the shortsegment small bowel and mesentery through the right cecal fossa (arrow). gutter laterally and the mesentery medially.

In our case, herniation of the jejunum through the cecal fossa was found during the operation. The clinical symptoms of internal hernias may range from intermittent mild digestive complaints to acute-onset incarceration. The major symptoms are obstructive symptoms of abdominal pain, nausea, vomiting, constipation and obstipation [8].

CT allows advanced diagnosis of intestinal obstruction because it provides more information about the cause than do either Xray or contrast studies. In addition to demonstrating the presence of extraluminal lesions, such as masses, adenopathy, soft tissue infiltration, fluid collections, abscesses and vascular anomalies $[9,10]$, the greatest advantage of CT is the diagnosis of early or partial obstruction, closed loop obstruction and multiple segments of obstruction. Dilatation of small intestine loops with a transitional zone adjacent to the cecum or an edematous small bowel located lateral to the cecum allows a paracecal hernia to

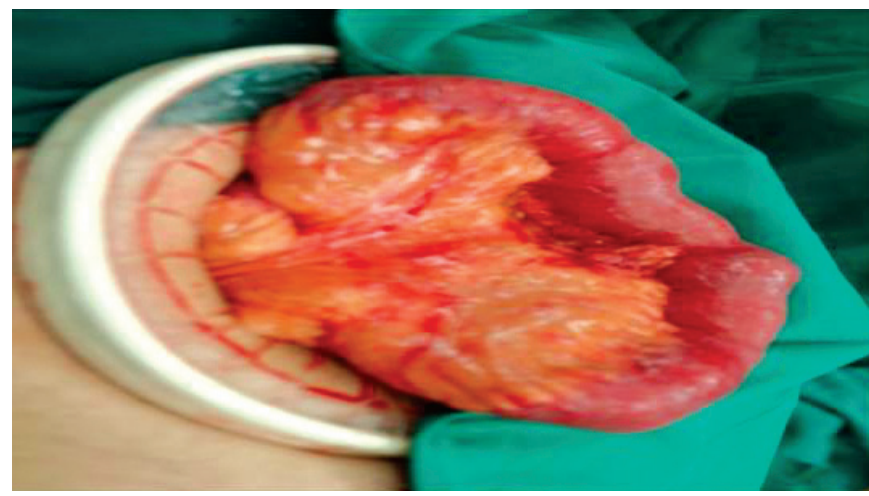

Fig. 3. Intraoperative finding of the entrapped jejunum after paracecal herniation had been reduced and the bowel had been confirmed to be viable.
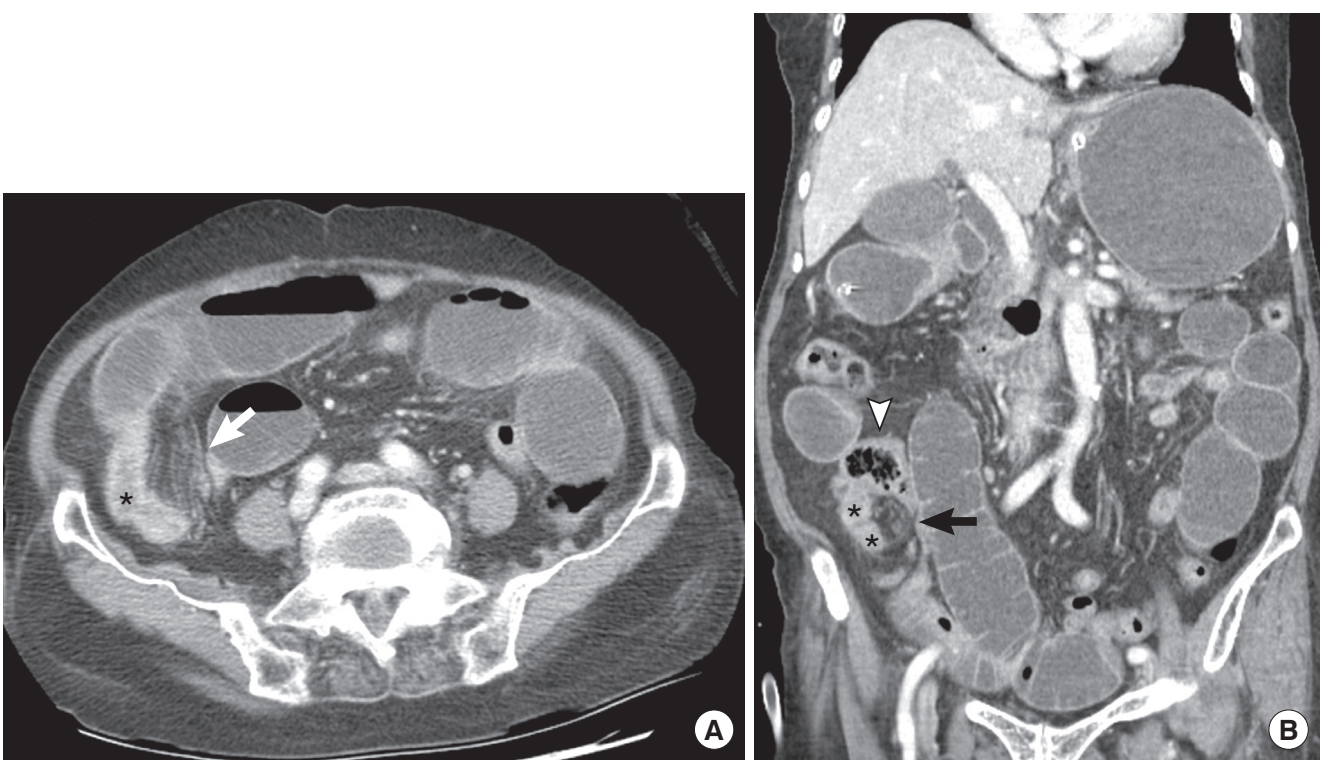

Fig. 2. (A) Cluster of a collapsed, herniated small bowel (asterisk), and (B) cluster of small bowel mesentery (arrow) are noted in the inferolateral aspect of the cecum (arrowhead). 


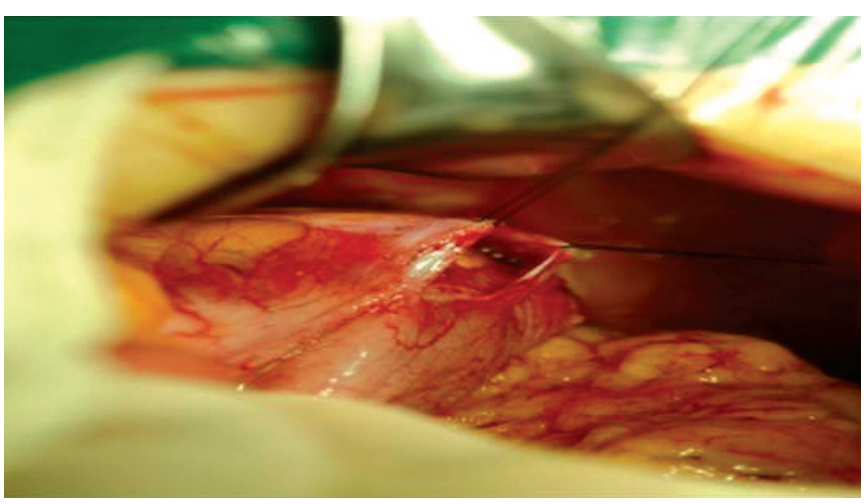

Fig. 4. Demonstration of the cecal fossa, which is formed by two peritoneal folds.

be diagnosed with high certainty.

Almost always the treatment for small bowel obstruction caused by a paracecal hernia is surgical intervention. Recently, the laparoscopic technique has been found to be useful for the diagnosis and treatment of bowel obstructions.

\section{CONFLICT OF INTEREST}

No potential conflict of interest relevant to this article was reported.

\section{REFERENCES}

1. Ghahremani GG. Internal abdominal hernias. Surg Clin North Am 1984;64:393-406.

2. Leffall LD Jr, Quander J, Syphax B. Strangulation intestinal obstruction. Arch Surg 1965;91:592-6.

3. Omori $\mathrm{H}$, Asahi $\mathrm{H}$, Inoue $\mathrm{Y}$, Irinoda $\mathrm{T}$, Saito K. Laparoscopic paracecal hernia repair. J Laparoendosc Adv Surg Tech A 2003; 13:55-7.

4. Rivkind AI, Shiloni E, Muggia-Sullam M, Weiss Y, Lax E, Freund HR. Paracecal hernia: a cause of intestinal obstruction. Dis Colon Rectum 1986;29:752-4.

5. Schumpelick V, Dreuw B, Ophoff K, Prescher A. Appendix and cecum. Embryology, anatomy, and surgical applications. Surg Clin North Am 2000;80:295-318.

6. Meyer A, Nowotony K, Poeschl M. Internal hernias of the ileocecal region. Ergeb Chir Orthop 1963;44:176-204.

7. Bass J Jr, Longley BJ. Paracecal hernia: case report and review of the literature. Am Surg 1976;42:285-8.

8. Ghiassi S, Nguyen SQ, Divino CM, Byrn JC, Schlager A. Internal hernias: clinical findings, management, and outcomes in 49 nonbariatric cases. J Gastrointest Surg 2007;11:291-5.

9. Furukawa A, Yamasaki M, Furuichi K, Yokoyama K, Nagata T, Takahashi M, et al. Helical CT in the diagnosis of small bowel obstruction. Radiographics 2001;21:341-55.

10. Boudiaf M, Soyer P, Terem C, Pelage JP, Maissiat E, Rymer R. CT evaluation of small bowel obstruction. Radiographics 2001;21: 613-24. 